\title{
Instability Model of a Coal Wall with Large Mining Height under Excavation Unloading Conditions
}

\author{
Lei Li ${ }^{1,2}$ and Feng zhang ${ }^{3,0}{ }^{3,4}$ \\ ${ }^{1}$ Business Division of Mining Design of Tiandi Technology Co., Ltd., Beijing 100013, China \\ ${ }^{2}$ Mining Research Division of China Coal Research Institute, Beijing 100013, China \\ ${ }^{3}$ State Key Laboratory of Mining Response and Disaster Prevention and Control in Deep Coal Mines, \\ Anhui University of Science and Technology, Huainan, Anhui Province 232001, China \\ ${ }^{4}$ State Key Laboratory of Water Resource Protection and Utilization in Coal Mining, Beijing 100120, China \\ Correspondence should be addressed to Lei Li; lilei@tdkcsj.com
}

Received 14 May 2020; Revised 20 September 2020; Accepted 20 October 2020; Published 12 November 2020

Academic Editor: Hailing Kong

Copyright (c) 2020 Lei Li and Feng Zhang. This is an open access article distributed under the Creative Commons Attribution License, which permits unrestricted use, distribution, and reproduction in any medium, provided the original work is properly cited.

\begin{abstract}
On the basis of the stress field characteristics of surrounding rocks at a coal wall on a working face with a large mining height, the theories of unloading rock mass mechanics and fracture mechanics were used to establish a model of the excavation unloading field effect of the coal wall, and its instability mechanism under the action of unloading stress field was analyzed. Results show that the coal mining process is the unloading process of coal and rock masses, and the stress field of surrounding rocks at the coal wall turns into an unloading stress field that consists of original and unloading stresses. Under the action of unloading stress field, cracks in the coal wall will undergo instability, propagation, and combination in the form of composite-type cracks and will gradually evolve into a wedge structure. The wedge stability is inversely related to roof pressure $P_{0}$, unloading force $T$, and intersection angle $\varphi$ of structural planes. Elevating the wall-supporting force $P_{h}$, the initial supporting force of supports on the working face and the cohesion $C$ of coal body can effectively control the occurrence of coal wall caving accidents and contribute to the safe mining of working faces with a large mining height.
\end{abstract}

\section{Introduction}

Fully mechanized underground coal mining with a large mining height is the development direction of thick coal mining in China. However, enlarging the mining height aggravates the probability of coal wall caving on the working face $[1-3]$ and restricts the application of fully mechanized coal mining technology in thick coal seam. Current methods of theoretically analyzing coal wall caving causes and mechanism, such as crack-layer plate structural model [4-6], compressive bar structural model $[7,8]$, wedge stability model [9], mechanical model of coal wall sliding surface [10], or coal wall shear failure model [11], neglect the influence of the coal mining-induced unloading effect. The theory of unloading rock mass mechanics states that the excavation process of rock and earth masses is actually a mechanical unloading process of rock masses [12]. Jointed rock masses in the loading process generally have good mechanical properties, but rock masses are turned from compressive state into tensile state under excavation unloading, and their mechanical properties will be rapidly degraded; as a result, the mechanical characteristics of rock masses under unloading condition are inconsistent with those under loading condition [13-15]. Therefore, the coal rock mass near the coal wall formed by coal seam excavation is analyzed as an unloading rock mass, which conforms to the characteristics of the engineering rock mass, and it has practical engineering significance. On the basis of the theories of unloading rock mass and fracture mechanics, the fracture instability mechanism of a coal wall under the action of unloading stress field was investigated, the fracture instability criterion for the coal wall and the influencing factors 
of its instability were acquired, and a new framework of using the theory of unloading rock mass mechanics to analyze coal wall fracture instability was opened.

\section{Characteristics of Coal Excavation-Induced Unloading Field Effect}

2.1. Principle of Unloading Analysis. The theory of unloading rock mass mechanics posits that excavation unloading effect is equivalent to applying a reverse tensile stress in the rock mass under initial stress. Thus, unloading stress can be equivalent to a tensile stress that acts upon the initial rock mass, and its maximum value is $\sigma_{0}+R_{t}\left(\sigma_{0}\right.$ is the initial stress, $R_{t}$ is the tensile strength of rock mass, and $\sigma_{0}+R_{t}$ is the equivalent tensile strength of rock mass). The unloading problem of rock mass during mining can be decomposed into the joint action model of initial and mining unloading stresses, as shown in Figure 1, where $\triangle \sigma$ is the unloading stress.

2.2. Stress Field of the Coal Body nearby the Coal Wall and Its Failure. In coal excavation process, the coal body nearby the coal wall will also bear the action of the excavation-induced unloading stress in addition to the stress of the primary rock. The stress condition is shown in Figure 2.

Given that original cracks or defects exist in the coal body, the quality of the coal nearby the coal wall will be gradually degraded under the unloading stress field that consists of primary rock stress (compressive stress) and unloading stress (tensile stress). After the excavation of the roadway, the original rock stress is redistributed, and the stress concentration appears in the surrounding rock of the roadway, which generally does not exceed 5 times the radius of the roadway. For the coal body nearby the coal wall of the working face with a large mining height, the coal wall will easily experience tensile or shear failure under the joint action of compressive and tensile stresses. When lateral confining pressure is moderate and lower than brittle-plastic transition value, the coal wall can easily undergo dislocation or shear failure $[5,16]$. The occurrence of the abovementioned failure mode is closely related to crack propagation and coalescence.

2.3. Mechanical Analysis of Crack Propagation. For the convenience of analysis, this study assumes that an oblique crack exists in the coal body, where its length is $2 a$ and its dip angle is $\beta$. The crack propagation model, as shown in Figure 3 , is established under the action of unloading stress field. Given the existence of unloading stress, crack propagation is controlled by types I and II stress intensity factors $K_{\mathrm{I}}$ and $K_{\mathrm{II}}$, and its propagation characteristics can be described by a composite-type crack model. In accordance with the superposition principle, the stress intensity factor at the crack end, as shown in Figure 3, can be expressed as the superposition of stress intensity factor caused by simple loading [17] (Figure 4). Therefore, the stress intensity factor of the composite-type crack is expressed as below.

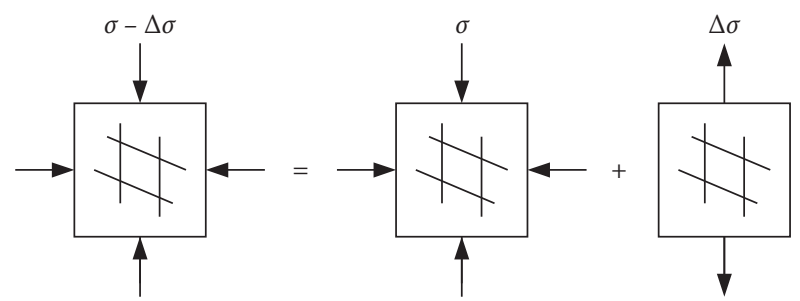

Figure 1: Graph of unloading field effect.

$$
\left.\begin{array}{l}
K_{\mathrm{I}}=\left(\Delta \sigma \sin ^{2} \beta-\sigma\right) \sqrt{\pi a}, \\
K_{\mathrm{II}}=\Delta \sigma \sqrt{\pi a} \sin \beta \cos \beta .
\end{array}\right\}
$$

According to the theory of the maximum circumferential stress in fracture mechanics [18-20], the breaking angle $\theta_{0}$ of the composite-type crack satisfies the following condition:

$$
k_{\mathrm{I}} \sin \theta_{0}+k_{\mathrm{II}}\left(3 \cos \theta_{0}-1\right)=0 \text {. }
$$

Its fracture criterion is

$$
\left[K_{\mathrm{I}} \cos ^{2} \frac{\theta_{0}}{2}-\frac{3}{2} K_{\mathrm{II}} \sin \theta_{0}\right] \cos \frac{\theta_{0}}{2}=K_{\mathrm{IC}} .
$$

We set $\alpha=K_{\mathrm{I}} / K_{\mathrm{II}}$. Then, we have

$$
\alpha=\frac{\triangle \sigma \sin ^{2} \beta-\sigma}{\triangle \sigma \sin \beta \cos \beta} .
$$

From equation (2), we can obtain the following:

$$
\begin{aligned}
\cos \theta_{0} & =\frac{3 \pm \sqrt{\alpha^{4}+8 \alpha^{2}}}{\alpha^{2}+9}, \\
\cos \frac{\theta_{0}}{2} & = \pm \sqrt{\frac{1+\cos \theta_{0}}{2}}, \\
& = \pm \sqrt{\frac{\alpha^{2}+12 \pm \sqrt{\alpha^{4}+8 \alpha^{2}}}{2\left(\alpha^{2}+9\right)}} .
\end{aligned}
$$

From comprehensive formulas (3), (4), and (5), we can get

$$
\begin{aligned}
& {\left[\begin{array}{c}
\frac{\alpha^{3}+12 \alpha \pm \alpha \sqrt{\alpha^{4}+8 \alpha^{2}}}{2\left(\alpha^{2}+9\right)} \\
-\frac{3}{2 \alpha}\left(1-\frac{9 \pm 3 \sqrt{\alpha^{4}+8 \alpha^{2}}}{\alpha^{2}+9}\right)
\end{array}\right]} \\
& *\left( \pm \sqrt{\frac{\alpha^{2}+12 \pm \sqrt{\alpha^{4}+8 \alpha^{2}}}{2\left(\alpha^{2}+9\right)}}\right), \\
& =\frac{K_{\mathrm{IC}}}{\Delta \sigma \sqrt{\pi a} \sin \beta \cos \beta} .
\end{aligned}
$$




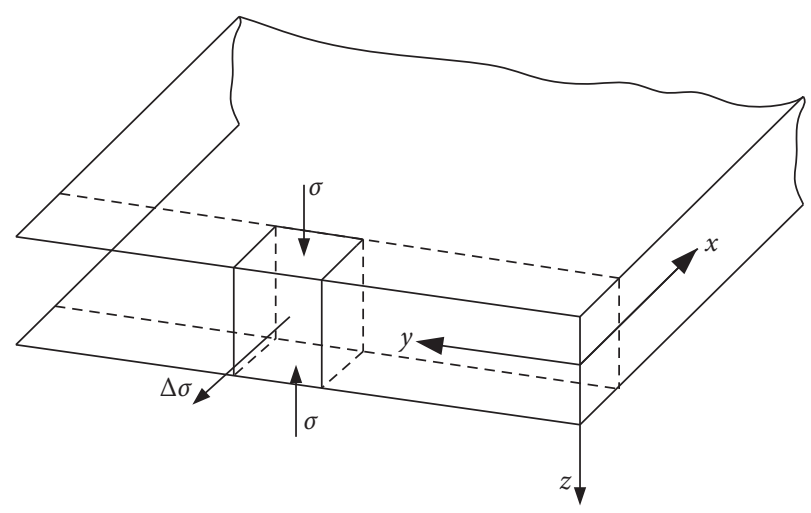

(a)

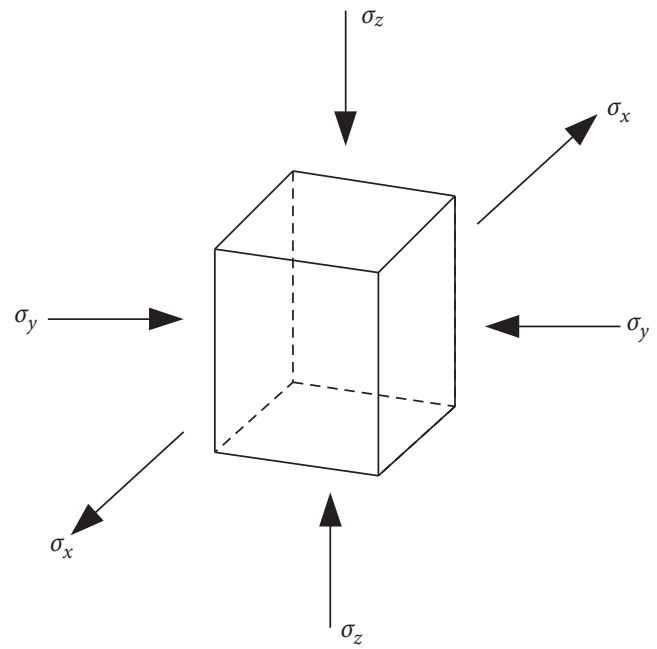

(b)

Figure 2: Unloading stress field in the coal body at the coal wall. Force diagram of the (a) coal body and (b) coal units at the coal wall on the working face.

We set $m=K_{\mathrm{IC}} / \triangle \sigma \sqrt{\pi a} \sin \beta \cos \beta$ and $0<\theta_{0}<\pi / 2$. Then, equation (8) of $\alpha$ about $m$ can be solved, and equation (4) can be combined to determine the relationships among ultimate compressive stress $\sigma$, unloading stress $\triangle \sigma$ (tensile stress), crack angle $\beta$, fracture toughness $K_{\mathrm{IC}}$, and initial crack length $a$, as shown in equation (9).

$$
\begin{aligned}
& \alpha=\frac{m}{3}-\frac{2^{1 / 3}\left(30 m^{2}-m^{4}\right)}{3 m\left(-216 m^{2}+153 m^{4}+2 m^{6}+3 \sqrt{3} \sqrt{1728 m^{4}+1552 m^{6}+435 m^{8}+36 m^{10}}\right)^{1 / 3}}, \\
& +\frac{\left(-216 m^{2}+153 m^{4}+2 m^{6}+3 \sqrt{3} \sqrt{1728 m^{4}+1552 m^{6}+435 m^{8}+36 m^{10}}\right)^{1 / 3}}{32^{1 / 3} m}, \\
& \sigma=\Delta \sigma\left(\begin{array}{c}
\sin \beta-\frac{m}{3}-\frac{2^{1 / 3}\left(30 m^{2}-m^{4}\right)}{3 m\left(\begin{array}{c}
-216 m^{2}+153 m^{4}+2 m^{6} \\
+3 \sqrt{3} \sqrt{1728 m^{4}+1552 m^{6}+435 m^{8}+36 m^{10}}
\end{array}\right)^{1 / 3}} \\
\left(\begin{array}{c}
-216 m^{2}+153 m^{4}+2 m^{6} \\
+3 \sqrt{3} \sqrt{1728 m^{4}+1552 m^{6}+435 m^{8}+36 m^{10}}
\end{array}\right)^{1 / 3} \cos \beta
\end{array}\right) \sin \beta .
\end{aligned}
$$

When the crack angle $\beta$ and the material fracture toughness $K_{\text {IC }}$ are determined, the ultimate compressive stress $\sigma$ declines with the increase in the unloading stress $\triangle \sigma$. With the continuous advancement of the working face during the coal mining process, the stress in the coal body in front of the working face is gradually concentrated. The unloading stress is also gradually enlarged. When the compressive and unloading stresses satisfy equation (9), the crack in the jointed coal body will undergo instability, propagation, and combination. This condition will lead to a coal wall caving event during operation under a large mining height. When the composite-type crack in the coal body is propagated, its propagation direction will not be along the direction of the dip angle of original crack any longer, but it will present propagation at the angle of $\theta_{0}$. Therefore, the instability form of the coal body at the coal wall with a large quantity of cracks is not a simple layer-crack plate structure but an irregular polyhedron of a certain dip angle. This deduction can be verified through the characteristic analysis and statistics of many field caving accidents. 


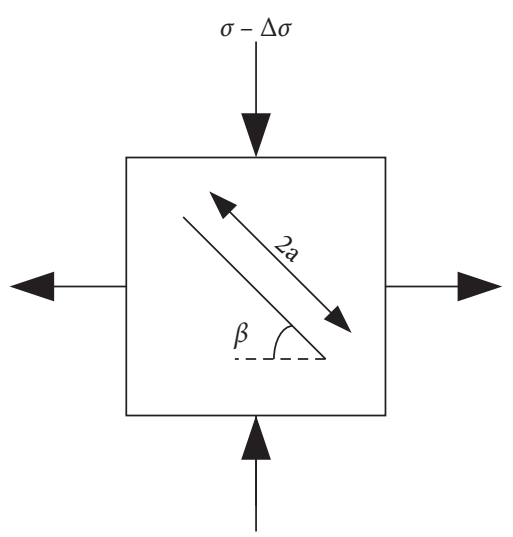

FIgURE 3: Composite crack propagation model.

\section{Instability Criterion for Wedge Structure at the Coal Wall}

The characteristic statistics of a large number of field coal wall caving accidents indicates that the geometric characteristics of the irregular polyhedron formed by instability, propagation, and combination of composite-type cracks can be simplified into a wedge structural model $[9,21]$. The stability of the coal wall can be analyzed through the stability of the wedge structure. The analytical model of wedge stability is constructed, as shown in Figure 5, to obtain the instability criterion for the coal wall wedge. In the figure, planes I and II are the structural planes that form after crack propagation and combination in the coal body. The line of intersection between these planes is $\mathrm{BD}$, and a wedge with quadrangular points $\mathrm{ABCD}$ is formed.

The dead weight of the wedge is set as $G$, the roof pressure as $P_{0}$, the unloading force as $T$, the horizontal wallsupporting force provided by wall-supporting plates as $P_{h}$, and the structural plane intersection angle as $\varphi$. The line of intersection $\mathrm{BD}$ is taken as $x$-axis, and the vertical line of the outward intersection is taken as $y$-axis to establish the coordinate system shown in Figure 5(b).

The force Nperpendicular to the line of intersection BD between structural planes is

$$
N=\left(P_{0}+G\right) \cos \varphi+\left(P_{h}-T\right) \sin \varphi .
$$

The force $\tau$ parallel to the line of intersection $\mathrm{BD}$ between structural planes is

$$
\tau=\left(P_{0}+G\right) \sin \varphi-\left(P_{h}-T\right) \cos \varphi
$$

$N$ is decomposed into $N_{\text {I }}$ perpendicular to structural plane I, and $N_{\text {II }}$ is perpendicular to structural plane II. We assume that the included angles between vertical plane of line of intersection $\mathrm{BD}$, which passes through structural planes I and II, and two structural planes are $\theta_{1}$ and $\theta_{2}$. The sliding direction of wedge is also assumed parallel to the line of intersection of the two structural planes, as shown in Figures 5(c) and 5(d). Then, it has

$$
\begin{gathered}
N_{\text {I }}=N \sin \theta_{1}, \\
N_{\text {II }}=N \sin \theta_{2} .
\end{gathered}
$$

The wedge stability coefficient $K$ can be expressed as

$$
K=\frac{f_{\mathrm{I}} N_{\mathrm{I}}+f_{\mathrm{II}} N_{\mathrm{II}}+C_{\mathrm{I}} S_{\mathrm{I}}+C_{\mathrm{II}} S_{\mathrm{II}}}{\left(P_{0}+G\right) \sin \varphi-\left(P_{h}-T\right) \cos \varphi}
$$

where $f_{\mathrm{I}}$ and $f_{\mathrm{II}}$ are the sliding coefficients of structural planes I and II, respectively; $C_{\mathrm{I}}$ and $C_{\mathrm{II}}$ are their cohesion coefficients; and $S_{\text {I }}$ and $S_{\text {II }}$ are the areas of their sliding surfaces.

By combining equations (10), (12), and (13), the expression of stability coefficient $K$ is determined as in equation (14). When $K<1$, the wedge at the coal wall will undergo instability failure to cause coal wall caving. When $K \geq 1$, the wedge will not experience any instability failure or the caving phenomenon.

$$
K=\frac{f_{\mathrm{I}}\left[\left(P_{0}+G\right) \cos \varphi+\left(P_{h}-T\right) \sin \varphi\right] \sin \theta_{1}+f_{\mathrm{II}}\left[\left(P_{0}+G\right) \cos \varphi+\left(P_{h}-T\right) \sin \varphi\right] \sin \theta_{2}+C_{\mathrm{I}} S_{\mathrm{I}}+C_{\mathrm{II}} S_{\mathrm{II}}}{\left(P_{0}+G\right) \sin \varphi-\left(P_{h}-T\right) \cos \varphi}
$$

In investigating the change relations of wedge stability with roof pressure, unloading force, and intersection angle between structural planes, we assume $\theta_{1}=\theta_{2}, f_{\mathrm{I}}=f_{\mathrm{II}}$, $C_{\mathrm{I}}=C_{\mathrm{II}}$, and $S_{\mathrm{I}}=S_{\mathrm{II}}$. Then, equation (14) can be simplified into the following form:

$$
K=\frac{2 f_{\mathrm{I}}\left[\begin{array}{c}
\left(P_{0}+G\right) \cos \varphi \\
+\left(P_{h}-T\right) \sin \varphi
\end{array}\right] \sin \theta_{1}+2 C_{\mathrm{I}} S_{\mathrm{I}}}{\left(P_{0}+G\right) \sin \varphi-\left(P_{h}-T\right) \cos \varphi} .
$$

A single-factor analysis by assigning values to the influencing parameters of wedge stability shows that, as roof pressure $P_{0}$, unloading force $T$, and intersection angle $\varphi$ between structural planes increase, the wedge stability is degraded. Moreover, the influence degrees of unloading force Tand intersection angle $\varphi$ are high, as shown in Figure 6.

As the wall-supporting force $P_{h}$ and cohesion Cof structural planes increase, wedge stability is also enhanced [9]. However, as the coal seam is continuously mined forward, the coal quality at the coal wall will be continuously degraded due to the existence of the excavation unloading effect, and its cohesion and internal frictional angle are continuously decreased, which further aggravates the wedge instability. Thus, on a working face with a large mining height, elevating wall-supporting force $P_{h}$, cohesion $C$ of coal body, and initial supporting force of supports on the working face can improve the wedge stability. 


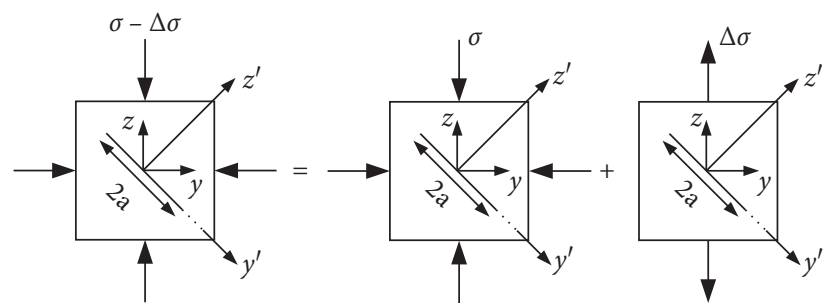

FIGURE 4: Superposition of stress intensity factor.

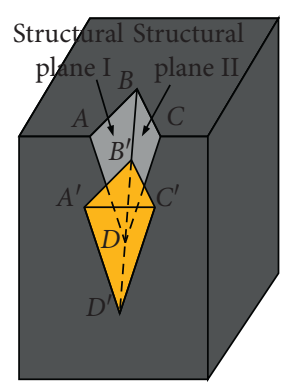

(a)

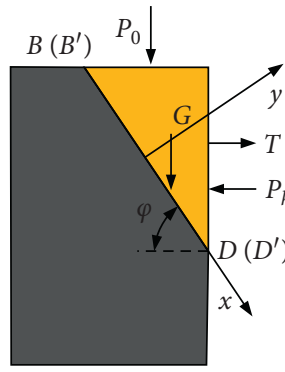

(b)

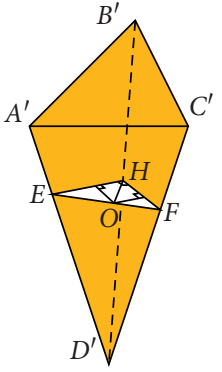

(c)

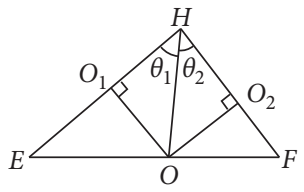

(d)

FIgURe 5: Analytical model of wedge stability at the coal wall.

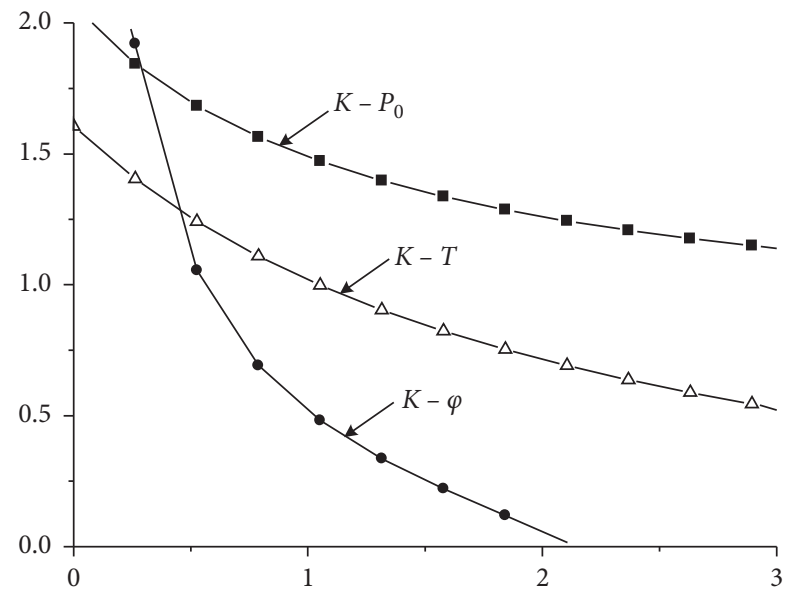

Figure 6: Diagram of unloading field effect.

\section{Stability Control Technology of the Coal Wall with a Large Mining Height}

The wedge instability mechanism at the coal wall indicates that improving the wedge stability helps enhance the stability of the coal wall and control coal wall caving. Therefore, the following measures can be taken to control coal wall caving in engineering practice

Wall-supporting force $P_{h}$ should be elevated. The stability of the coal wall on the working face with a large mining height, especially for "three-soft" coal seam, is poor due to the unloading effect. However, enlarging the wall-supporting force can generate a certain compensating and weakening effect on the unloading force. Thus, after the coal is cut through a coal machine, the wall-supporting plate should be timely opened to guarantee wedge stability.
Cohesion $C$ of the coal body at the coal wall should be elevated. Coal seam grouting or water injection can improve coal properties, increase coal wall cohesion, enlarge internal frictional angle, and enhance antishear ability and overall stability.

Initial supporting force of supports should be elevated. Initial supporting force is the force used by supports to proactively support the roof. The supports should be timely lifted after coal cutting and support advancing, and roofcontacted filling should be carried out to ensure sufficient initial supporting force, effectively mitigate rotation and subsidence of roof strata, keep peak supporting pressure away from the coal wall, and relieve coal wall pressure $P_{0}$. Accordingly, the wedge stability of coal wall can be controlled.

The advancement of the working face should be properly accelerated. The accelerated advancement of the working face shortens the exposure time of the coal wall and relieves the influence degree of the coal excavation unloading effect. Meanwhile, it also reduces the action time of the supporting pressure on the coal wall and the degree of coal damage and degradation. Accordingly, the coal wall caving degree can be decreased.

\section{Conclusions}

The coal mining process is the unloading process of coal and rock masses. The characteristics of coal excavation-induced unloading stress field were analyzed using the theory of unloading rock mass mechanics. The results showed that the stress field of surrounding rocks at the coal wall would be turned into an unloading stress field that consisted of original and unloading stresses. 
Under the action of unloading stress field, the cracks in the coal wall would undergo instability, propagation, and combination in the form of composite-type cracks and be gradually evolved into a wedge structure. Meanwhile, the propagation criterion for composite-type cracks under the existence of unloading stress was given in accordance with the theory of fracture mechanics.

The wedge instability criterion of the coal wall was obtained by establishing a mechanical model of the wedge stability of the coal wall. Specifically, when $K<1$, the coal wall wedge would experience instability failure to cause coal wall caving. In addition, the wedge stability would be degraded, and the coal wall could easily undergo caving with the increase in roof pressure $P_{0}$, unloading force $T$, and intersection angle $\varphi$ between structural planes.

The stability of the coal wall could be improved by elevating the wall-supporting force $P_{h}$, the coal cohesion $C$, and the initial supporting force and by properly accelerating the advancement of the working face to provide a guarantee for safe mining of working faces with a large mining height.

\section{Data Availability}

The data underlying the findings of this paper are publicly available.

\section{Conflicts of Interest}

The authors declare no conflicts of interest.

\section{Acknowledgments}

This work was financially supported by the Open Fund of "State Key Laboratory of Water Resource Protection and Utilization in Coal Mining" (SHJT-17-42.5).

\section{References}

[1] S.-H. Tu, Y. Yong, Y. Zhen et al., "Research situation and prospect of fully mechanized mining technology in thick coal seams in China," Procedia Earth and Planetary Science, vol. 1, no. 1, pp. 35-40, 2009.

[2] X. Z. Ma and G. X Xie, "Coal wall spalling mechanism and control technology of fully mechanized high cutting longwall coal mining face," Chinese Journal of Coal Science Technology, vol. 36, pp. 1-4, 2008, in Chinese.

[3] X. J. Wang, X. S. Qian, L. Q. Ma et al., "Research on large mining height technique for thick coal seams," Chinese Journal of Coal Science Technology, vol. 26, pp. 212-216, 2009, in Chinese.

[4] X. X. Miao, L. Q. An, and M. H. Zhai, "Model of rock barest for extension of slip fracture in palisades," Journal of China University of Mining and Technology, vol. 8, pp. 15-19, 1999, in Chinese.

[5] X. C. Zhang, X. X. Miao, and T. Q. Yang, "The layer-crackplate model and testing study of the rock burst in mines," Chinese Journal of Rock Mechanics and Engineering, vol. 18, pp. 507-511, 1999, in Chinese.

[6] H. L. Zhang, L. G. Wang, and H. Qin, "Study of spalling mechanism and control techniques of mining roadway," Chinese Journal of Rock Mechanics and Engineering, vol. 31, pp. 1462-1466, 2012, in Chinese.
[7] X. W. Yin, S. H. Yan, and Y. An, "Characters of the rib spalling in fully mechanized caving face with great mining height," Chinese Journal Mine Safety Science and Engineering.vol. 25, pp. 222-225, 2008, in Chinese.

[8] Y. Ning, "Mechanism and control technique of the rib spalling in fully mechanized mining face with great mining height," Journal of China Coal Society, vol. 34, pp. 50-52, 2009, in Chinese.

[9] Y. Yuan, S. H. Tu, X. T. Ma et al., "Coal wall stability of fully mechanized working face with great mining height in "three soft" coal seam and its control technology," Chinese Journal Mine Safety Science and Engineering.vol. 29, pp. 21-25, 2012, in Chinese.

[10] H. J. Hao and Y. Zhang, "Stability analysis of coal wall in fullseam cutting workface with fully-mechanized in thick seam," Chinese Journal of Liaoning Technical University, vol. 24, pp. 489-491, 2005, in Chinese.

[11] J. C. Wang, "Mechanism of the rib spalling and the controlling in the very soft coal seam," Journal of China Coal Society, vol. 32, pp. 785-788, 2007, in Chinese.

[12] J. L. Li, Unloading Rock Mass Mechanics, China Water Power Press, Beijing, China, 2003, in Chinese.

[13] X. P. Zhou, Q. L. Ha, Y. X. Zhang et al., "Analysis of localization of deformation and complete stress strain relation for mesoscopic heterogenous brittle rock materials when axial stress isohel constant while lateral confinement is reduced," Chinese Journal of Rock Mechanics and Engineering, vol. 24, pp. 3236-3245, 2005, in Chinese.

[14] H. L. Hu, Study on Sensitivity of Stable Parameters for Rock Slope and Mechanical Parameters of Excavation Unloading Rock Mass, Three Gorges University. College of Civil and Hydropower Engineering, Yichang: China, 2008, in Chinese.

[15] J. L. Pei, J. F. Liu, and J. Xu, "Experimental study of mechanical properties of layered marble under unloading condition," Chinese Journal of Rock Mechanics and Engineering, vol. 28, pp. 2496-2502, 2009, in Chinese.

[16] L. N. D. Germanovich, A. V. Yskin, N. M. Syrul Nikov et al., "A model of the deformation and fracture of brittle materials with cracks under uniaxial compression," Mechanics of Solids, vol. 28, pp. 116-1288, 1993.

[17] B. K. Atkinson, Fracture Mechanics of Rock, Seismological Press, Beijing, China, 1992.

[18] Y. D. Li, Theory and Application of Fracture Mechanics, Weapon Industry Press, Beijing, China, 2005, in Chinese.

[19] Q. Gao, Engineering Fracture Mechanics, Chongqing University press, Chongqing, China, 1996, in Chinese.

[20] L. S. Tang, P. C. Zhang, and Y. Wang, "Propagation of the complex cracks in rocks without water pressure," China Journal of Acta Scientiarum Naturalium Universitatis Sunyatseni, vol. 41, pp. 83-90, 2002, in Chinese.

[21] Q. Gao, X. J. Yi, and X. Y. Zhao, "Discussion and analysis of wedge sliding and its stability," China Journal of Subgrade Engineering, vol. 12, pp. 115-116, 2008, in Chinese. 